\title{
Possibility Precedes Actuality
}

\author{
Tuomas E. Tahko ${ }^{1}$ (D)
}

Received: 3 July 2021 / Accepted: 5 January 2022

(c) The Author(s) 2022

\begin{abstract}
This paper is inspired by and develops on E. J. Lowe's work, who writes in his book The Possibility of Metaphysics that 'metaphysical possibility is an inescapable determinant of actuality' (1998: 9). Metaphysics deals with possibilities - metaphysical possibilities - but is not able to determine what is actual without the help of empirical research. Accordingly, a delimitation of the space of possibilities is required. The resulting - controversial - picture is that we generally need to know whether something is possible before we can know whether it is actual. In order to appreciate this picture, we need to understand Lowe's slogan: 'essence precedes existence' (Lowe 2008: 40). This slogan has both an ontological and an epistemic reading. The ontological reading is related to the now familiar idea that essence grounds modality, as popularised by Kit Fine. The epistemic reading suggests that we can know the essence of some entity before we know whether or not that entity exists. However, this idea is often met with puzzlement and Lowe himself sadly passed away before he had a chance to clarify this framework. I will present the framework as I understand it, develop it on my own terms, and put forward a qualified defence of it. I will also illustrate how the framework can be put to use with a case study concerning the discovery of transuranic elements.
\end{abstract}

\section{Introduction: the Role of Essence}

The title of this paper is inspired by E. J. Lowe's work, who writes in his book The Possibility of Metaphysics that 'metaphysical possibility is an inescapable determinant of actuality' (1998: 9). The modal metaphysics that motivates this statement is thoroughly essentialist and in order to understand how possibility precedes actuality,

Tuomas E. Tahko

tuomas.tahko@bristol.ac.uk

1 Department of Philosophy, University of Bristol, Cotham House, Cotham Hill, UK, Bristol BS6 6JL 
we must understand the closely related slogan: 'essence precedes existence', which Lowe further qualifies: 'by this I mean that the former precedes the latter both ontologically and epistemically' (Lowe, 2008: 40). ${ }^{1}$ So, the slogan has both an ontological and an epistemic reading. The ontological reading is related to the familiar neo-Aristotelian idea that essence grounds modality, as popularised by Fine (e.g., 1994). In other words, not all necessary truths about a given entity $x$ are essential truths about $x$, but all necessary truths are true in virtue of essential truths (about some entity or other). This implies that essential truths about $x$ are a proper subset of the necessary truths about $x$, but even those necessary truths about $x$ that are not essential truths about $x$ are nevertheless essential truths about some entity or other. According to this view, all modal truths can be analysed in terms of essential truths.

On this view, which is now quite widely accepted, we should not reduce essence to de re modal properties - rather, it is modality that reduces to essence (see Correia, 2012 for discussion). Lowe himself adds that it is a 'precondition of something's existing that its essence-along with the essences of other existing things-does not preclude its existence' (Lowe, 2008: 40). My purpose in this paper is to clarify and develop on these ideas. This will entail a fair amount of Lowe exegesis, and I will also respond to various critical remarks on Lowe's work on his behalf. But ultimately, I am putting forward my own version of a Lowe-inspired framework, which does deviate from his views in some important regards. For instance, as will become clear, I am somewhat less committed to the epistemic reading of Lowe's slogans, at least if they are understood in an absolute sense.

I will assume the neo-Aristotelian view of the relationship between essence and modality, which also underpins Lowe's framework. Although I closely follow Lowe's framework, I will not attempt to be entirely faithful to it. Inevitably, some controversial assumptions have to be taken for granted, since I do not have the space to defend all aspects of the framework here. Finally, I will be restricting my focus to examples from the empirical sciences rather than mathematics or logic - not because the latter wouldn't be interesting, but because the applicability of Lowe's slogans is arguably more debatable in the empirical realm. ${ }^{2}$ Relatedly, I will mainly be discussing cases of scientific reasoning and knowledge rather than 'everyday' contexts.

The epistemic reading of 'essence precedes existence' suggests that we can know the essence of some entity before we know whether or not that entity exists. It is worth noting that Lowe (2008: 40-41fn.32) qualifies this reading by saying that, in some cases, we might come to know the essence of an entity simultaneously with its discovery, so even Lowe himself may not have intended the slogan to be read in the sense that it would be necessary for us to always know the essence of an entity prior to its existence. Lowe doesn't mention any examples of this, but one plausible candidate might be a case where an experiment produces unexpected results, e.g.,

\footnotetext{
${ }_{1}$ For some, this slogan (or its converse) may be reminiscent of Sartre, but I assure the reader that this is merely a coincidence, as Lowe's use of the slogan has no connection to the existentialist tradition.

${ }^{2}$ Lowe discussed examples from geometry in his 2012 paper, and these have received some attention, e.g., in Horvath 2014, Sgaravatti 2016, Tahko 2017, and Casullo 2020. I will not be focusing on these examples, but I will address the commentaries in Sect. 3 .
} 
unpredicted decay products in high energy physics experiments. This leads Lowe to say that we can at least in general know the essence of some entity before knowing whether it exists. So, the epistemic reading of 'essence precedes existence' is not absolute. In any case, if true, it seems that we can also know the essences of many things which do not exist (and perhaps never will). The thought here is that we can know what something would be if it were to exist. However, this idea is often met with puzzlement and Lowe never fully clarified this framework. For one thing, how do we assess statements about the essences of non-existent things, and what are their truthmakers? I propose that we can analyse them in the same way that we analyse essences in general, and that the truthmakers may generally be found in actuality. I regard this to be partly an a priori endeavour, but I will not put much weight on this epistemic claim in the present context - I regard a priori and a posteriori inquiry to be very closely intertwined (for further discussion on this distinction, see, e.g., Williamson, 2013, Casullo, 2015, and Tahko, 2018).

It may be helpful to take a step back and outline the six logical alternatives that we have at this point. ${ }^{3}$ These alternatives have been outlined by Vaidya (2017) in a reconstruction of Lowe's position. Vaidya uses the label 'existentialism' (which should not here be understood in its usual sense) to describe the converse of Lowe's 'essence precedes existence', and 'entanglement' to describe the idea that there is no (necessary) priority ordering between $x$ 's essence and $x$ 's existence. Vaidya (2017: 107-110) summarises the options as follows (the acronyms are my addition):

(O-EX) Ontological existentialism: $x$ 's existence necessarily precedes $x$ 's essence.

(O-ES) Ontological essentialism: x's essence necessarily precedes $x$ 's existence.

(E-EX) Epistemic existentialism: knowledge of x's existence necessarily precedes knowledge of $x$ 's essence.

(E-ES) Epistemic essentialism: knowledge of $x$ 's essence necessarily precedes knowledge of $x$ 's existence.

(O-EN) Ontological entanglement: $x$ 's existence is entangled with $x$ 's essence.

(E-EN) Epistemological entanglement: knowledge of $x$ 's existence is entangled with knowledge of $x$ 's essence.

As we have seen, Lowe defends, by and large, the combination of (O-ES) and (E-ES), although as I just pointed out he does leave open the option that we might come to know the essence of an entity simultaneously with its discovery, which points toward (E-EN). This is at least partly the result of the added 'necessarily' in Vaidya's formulation - Lowe himself does not formulate the idea of essence preceding existence in these absolute terms, and I believe that the reason for this may be precisely because he saw the pull of something like (E-EN), at least in some cases (which already rules out the necessity of (E-ES)). We can also see this in Lowe's later conception of the interplay between the a priori and the a posteriori, which he

\footnotetext{
3 Thanks to an anonymous reviewer for pointing this out.
} 
conceives as proceeding in a 'cyclical manner, by alternating stages of a priori and a posteriori inquiry' (Lowe, 2014: 257). All this suggests that, despite first appearances, it might be best to read Lowe as defending a combination of (O-ES) and something like (E-EN), which is also the line that I favour. We will return to some of these issues below, but let me also point out that I am uncertain about how to read (O-EN), at least unless we accept the possibility of metaphysically vague existence. Indeed, Vaidya in fact suggests that 'The ontological variety of entanglement is either trivial or incoherent' (2017: 110). Accordingly, we can set it aside in what follows.

One further point of clarification is in order before we get going. This concerns the rather difficult question of what essences are. Lowe sometimes refers to his own, broadly Aristotelian view of essence as 'serious essentialism' (e.g., Lowe, 2013: 144). But the way that he qualifies the view is not always most helpful, as following Locke he suggests simply that the essence of $x$ is the very identity of $x$. Another popular way of capturing what essences are is in terms of the Aristotelian notion of real definition. Both Lowe and Fine sometimes resort to this idea, but this notion as well may be understood in a number of ways, and those who find the notion of 'essence' mysterious are unlikely to be much more impressed by 'real definition' (see Rosen, 2015 for discussion). So, let me try to say a bit more.

For Lowe, it is important that essences are not entities themselves - I agree. ${ }^{4}$ Further, he takes it that all entities have an essence. I will assume that this is true. As Lowe notes, if all entities have an essence and essences themselves were entities, there would be a threat of infinite regress (Lowe, 2008: 39; but see also Spinelli, 2018 and Wallner, 2020 for further discussion). If essences are not entities themselves, then what are they? I propose to read 'essence' as 'the identity and existence conditions of an entity'. Once we know these conditions, we know the essence; we may express this essence in terms of a set of identity and existence conditions or in terms of a proposition listing these conditions, but the essence itself, in my view, is not a set or a proposition. ${ }^{5}$ I believe that this comes close to Lowe's view of the matter, but things are somewhat less clear with other broadly Aristotelian versions of essentialism, such as Fine's, who sometimes writes as if essences themselves are propositions: 'we may identify the being or essence of $\mathrm{x}$ with the collection of propositions that are true in virtue of its identity' (Fine, 1995: 275). If 'identify' is here read in terms of numerical identity, then essences would turn out to be collections of propositions. But I stress that this is not a reading that I accept; the propositions that express essences are not themselves essences, as otherwise essences would turn out to be entities after all.

It is quite obviously key to our analysis of essence to be clear about what essences are, so let me, again, state this as clearly as possible: the essence of an entity is not

\footnotetext{
4 'Entity', as Lowe understands it, refers to all kinds of beings, things that do or could exist, such as material bodies, but also concepts, properties, sets, numbers, and propositions - anything that falls in an ontological category (see Lowe 2008: 35).

5 Accordingly, when I use the notion of 'essence' below, this should be read in line with this interpretation.
} 
a thing or collection of things, it is the identity of a thing in the sense that the conditions captured by the essence express the modal profile of the entity and determine how one entity is distinct from another. I should note that this is not supposed to imply anything like a primitive haecceity. Rather, the view is that the identity and existence conditions of an entity specify how it differs from and depends on other entities. The ultimate basis of these conditions is the categorial structure of reality and the formal ontological relations, such as instantiation and characterization, that govern that structure. ${ }^{6}$ Lowe famously defends a four-category ontology (see Lowe, 2006a), but we need not commit to any specific theory of categories in order to get the present framework going. What is important is that the basis of the identity and existence conditions of entities is a matter of where they are positioned in the categorial structure and how they are related to entities of other categories. Now, since the essence itself is not a further entity or thing, this is the first hint of why we can know about the essences of non-existent entities as well: there is no mysterious Platonic realm of essences that we need to access, we can state the essence of a nonexistent entity simply by listing its identity and existence conditions. In a moment, I will clarify what this means in practice.

Finally, we should take note of the distinction between general and individual essences. ${ }^{7}$ This is an important distinction for Lowe (e.g., 2013: 145), but personally I am rather sceptical about individual essences, and this may be the single most important deviation that I will make from Lowe's own framework. General essences, such as the essence of the natural kind gold, will be my main focus - although there may be reasons to be sceptical about some general essences as well, such as those of biological species. I take it that general essences are nevertheless somewhat less controversial than individual essences, and in fact in this regard my own view is perhaps closer to traditional 'Aristotelian essentialism' than Lowe's, since it connects essentiality with what it is to be a natural kind (cf. Brody, 1973). It follows that essences of artificial objects, such as tables and chairs, are also among the more controversial cases, at least if we wish to assign them anything more than the general essence of artefact. On my preferred conception of essence, the identity and existence conditions of individuals will concern their general rather than individual features, specifically, features regarding their kind. Having said that, this distinction will not have any particularly important implications for the discussion that follows.

In Sect. 2, I will first clarify the role of essence for the topic at hand. In particular, I will discuss the sense in which essences constrain the space of metaphysical

\footnotetext{
${ }^{6}$ See Smith and Mulligan 1983 for background and Lowe 2006a: Ch. 3 for further clarification of formal ontological relations. These are internal relations in the sense that they hold necessarily, given the existence of their relata.

${ }^{7}$ Lowe (2008: 35) defines the distinction as follows: ' $\mathrm{X}$ 's general essence is what it is to be a $K$, while $X$ 's individual essence is what it is to be the individual of kind $K$ that $X$ is, as opposed to any other individual of that kind.' The idea of general essence can also be understood in terms of objectual essence (as discussed in Correia 2006: 754): 'describing the essence or some essential features of a given object $a$ is just giving an answer, be it complete or only partial, to the metaphysical question as to what $a$ is.' So, in speaking of the general essence of an entity, we are concerned with its objectual essence, considered solely with respect to its general features rather than any features unique to it.
} 
modality. In Sect. 3, I will return to the epistemic reading of "possibility precedes actuality' and consider some recent objections to this reading. In Sect. 4, I turn my attention to a case study concerning transuranic elements and demonstrate that we can know the essences of at least some non-existent entities. In Sect. 5, I will generalise this lesson and outline the resulting framework for metaphysical modality, focusing on the problem of actuality. To conclude this section, let me summarise three important assumptions that I will not defend further in what follows:

(1) Essences are not entities.

(2) Every entity has a general essence.

(3) Having an essence does not entail that an entity exists or even could exist.

\section{Essence Precedes Existence}

As noted, Lowe's slogan 'essence precedes existence' has both an ontological and an epistemic reading. Lowe (2008, see also Lowe 2012) focused his efforts on clarifying the epistemic reading and this has been discussed in detail by others before (e.g., Vaidya, 2010, Tahko, 2017, 2018, Vaidya \& Wallner, 2021; see also Oderberg, 2011 and Koslicki, 2018). I will discuss this reading in Sect. 3, but my primary goal here is to clarify the more neglected ontological reading. Lowe himself connects this reading with Fine's work, clearly having the following passage from Fine's book Modality and Tense in mind:

Although there may be something about how the matter of Socrates turns out that is relevant to its constituting a man, there is nothing about how Socrates himself turns out that is relevant to his being a man. If I am right, then this means that philosophers have been mistaken in thinking that Socrates cannot be a man unless he exists, that existence must precede essence. Socrates must already be a man, if I may put it that way, before the question of how things turn out for him can even arise. (Fine, 2005: 11.)

This idea of essence preceding existence is obviously linked to Fine's earlier work on essence, where it is perceived as the ground of modality, but I think that the underlying framework that both Fine and Lowe have in mind has not been fully laid out in the short passages that I've quoted. Moreover, the examples used, like Socrates being a man, may not always be as helpful as intended. Let me try to express what I take that underlying framework to be without resorting to any potentially controversial examples. Given that the essences of entities express the identity and existence conditions of those entities, it is possible to state essences of entities that do not or even could not exist. ${ }^{8}$ Since the essence is no entity itself, there

\footnotetext{
${ }^{8}$ What would an entity that cannot exist be like? Well, a simple case would be entities that possess contradictory properties, such as being round and square. But a more interesting case would be an entity that cannot exist, say, because another entity that already exists - and exists necessarily - precludes its existence. I will not attempt to give examples of such cases, partly because it is very difficult to establish that something exists necessarily. However, see Kimpton-Nye 2021 for one such attempt; he examines the idea that it is necessarily the case that $\varphi$ iff nothing has a disposition for it to be the case that not- $\varphi$.
} 
is nothing mysterious about essences of non-existent entities. After all, the essence captures, in the form of identity and existence conditions, what it would take for a given entity to exist and what makes it the very entity that it is. All this, I take it, is also in the background of the passage I quoted from Lowe earlier: 'it is a precondition of something's existing that its essence-along with the essences of other existing things-does not preclude its existence' (2008: 40). Now, neither Fine nor Lowe explicitly state that essences concern the identity and existence conditions of entities, but we can find many passages where this type of conception of essence is implicit, especially in Lowe's work (e.g., 2008: 46-47).

So, to elucidate my own understanding of essence, we need to discuss what identity and existence conditions are. Here we eventually do have to resort to some examples, but I should immediately stress that these examples are all somewhat tentative, as I believe that it is in fact often quite difficult to determine what the true identity and existence conditions of some actual entity are. However, the good news is that since we can state the identity and existence conditions of non-existing entities as well, any logically coherent set of identity and existence conditions is a candidate for an entity that could exist. Why only a candidate? This is something that Lowe noticed, as we can see from the previously quoted passage: the essences of other existing things could preclude the existence of some entity that could otherwise exist. So, mere logical coherence is not enough, we also need to consider how an entity is - or would be - related to other entities. This means that we cannot consider essences individually if our hope is to ultimately determine what exists. Instead, we must consider all the implications that an entity's existence would have for the existence of other entities. These are modal implications: the existence of entity $x$ may make it impossible for entity $y$ to exist. Moreover, the existence of $x$ may necessitate the existence of $y$. This can happen in a number of ways. For instance, there is a sense in which my existence necessitates the existence of my parents, because I could not exist if they had not existed. But, of course, now that I do exist, my existence no longer necessitates their existence. This type of past existential dependence is an indication of the complexities that we need to consider: identity and existence conditions are often temporally relative.

Consider another simple example: methane $\left(\mathrm{CH}_{4}\right)$ molecules could not exist unless carbon and hydrogen existed. So, the existence of methane necessitates the existence of carbon. There is also some plausibility in the claim that methane essentially depends for its existence on carbon, although this depends on how we understand the essences of things like chemical substances. In any case, assuming, for the sake of argument, that a form of microstructural essentialism is true, the dependence at hand would be a form of generic essential dependence, which we may define as follows ${ }^{9}$ :

(GEN) $x$ depends $_{\mathrm{GEN}}$ for its existence upon $F \mathrm{~s}={ }_{\mathrm{df}}$ It is part of the essence of $x$ that $x$ exists only if some $F$ exists.

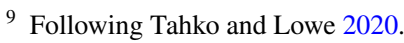


In the case at hand, the $F$ s would be carbon or hydrogen atoms. Much more generally, we might say that any complex entity that has its parts essentially (if there are any) will generically essentially depend on those parts for its existence. So, there will be a complex network of dependencies among the various entities that do, or could, exist. These relationships may be described in terms of different forms of ontological dependence, such as (GEN), which I will not discuss in detail here, partly for reasons of space and partly because there exists a comprehensive literature already (see e.g., Correia, 2008, Koslicki, 2012, and Tahko \& Lowe, 2020).

Let me instead take a step back and address some worries regarding Lowe's framework which have been put forward in the literature. This will also be an opportunity for me to make it clearer where I deviate from Lowe's views. I will then (in Sect. 4) move on to a somewhat more sophisticated example, which puts the present framework to use.

\section{The Epistemic Reading: Some Issues Regarding Lowe's Framework}

I'd like to briefly discuss a set of related issues that a number of authors have brought up regarding Lowe's framework. The focus here is on the epistemic reading of the thesis that essence precedes existence, that is: do we require knowledge of essence before we can know about actually existing things? I have in mind the contributions of Horvath (2014), Sgaravatti (2016), Tahko (2017), Casullo (2020), and Vaidya and Wallner (2021). ${ }^{10}$ In the present paper my primary interest is on the ontological reading, but of course in Lowe's own work these two readings are so closely related that it is difficult to distinguish them entirely.

Let me start, in chronological order, from Horvath (2014), who discusses Lowe's claim that because we can sometimes understand real definitions and hence 'grasp' the essences of some things, 'we can know at least sometimes that something is metaphysically necessary or possible: we can have some knowledge of metaphysical modality' (Lowe, 2012: 947). Horvath's main criticism is that, in Lowe's account, there is a gap between essential knowledge and modal knowledge, and Lowe needs the following bridge principle to address this (Horvath, 2014: 212) ${ }^{11}$ :

(P) Any essential truth is ipso facto a metaphysically necessary truth.

Horvath notes that $(\mathrm{P})$ itself is something that remains unexplained in Lowe's modal epistemology. Crucially, since essences themselves are not entities and hence do not have essences, $(\mathrm{P})$ cannot be known on the basis of our knowledge of essences.

\footnotetext{
${ }_{10}$ In fact, there is important background already in Roca-Royes 2010, but I will not discuss this in detail as Roca-Royes is focusing on Peacocke's rather than Lowe's account.

11 This is closely related to what Vaidya and Wallner (2021) call the problem of 'Modal Epistemic Friction' (PMEF), summarised nicely by Mallozzi: 'There must be some kind of push-back, or friction, on modal reasoning to make sure that it does not lead us astray but rather captures genuine possibility and necessity' (Mallozzi 2021: 1317). As an anonymous reviewer has helpfully pointed out, (PMEF) is a very general problem for epistemology of modality, but Horvath's objection comes close to a formulation of (PMEF) for a Lowe-type theory, as Vaidya and Wallner (2021: 1926) have suggested.
} 
Let me now move on to my previous response to this objection (Tahko, 2017), and Casullo's (2020) as well as Vaidya and Wallner's (2021) rejoinders. When I first picked up Horvath's challenge, I pointed out that since Horvath grants 'Lowe's Finean account of the relation between essence and modality' (Horvath, 2014: 210), there is already a bridge principle in place. The idea here is that on the Finean account of essence, all metaphysically necessary truths are true in virtue of essential truths, and so our knowledge of $(\mathrm{P})$ is already part of this framework if we accept Fine's influential examples about essence. I went on to present a reconstruction of Lowe's modal epistemology with this assumption in mind, but Casullo has recently argued that this reconstruction suffers from the same problem as Lowe's original account, namely, the 'failure to distinguish between knowing that $p$, where $p$ is an essential truth, and knowing that $p$ is an essential truth' (Casullo, 2020: 605). Moreover, Casullo maintains that even if the truth of the Finean framework is accepted, that does not address the question of how we know a bridge principle like $(\mathrm{P}) .{ }^{12} \mathrm{He}$ suggests that it's the failure to address this epistemic question that creates the gap in Lowe's (and my own) modal epistemology. Relatedly, Vaidya and Wallner summarise the Horvath-Tahko exchange by picking up on the idea that even if there is no 'metaphysical gap' between essence and modality, an epistemic gap nevertheless remains: "the mere truth of the claim that modality reduces to essence, one might argue, does not suffice for an epistemic subject to come to know a modal proposition directly by knowing an essentialist proposition without making any use of some bridge principle' (Vaidya \& Wallner, 2021: 1927, my emphasis).

It seems to me that the different parties in this debate may, at times, be speaking past each other. Let me attempt a reconciliation. To accept the Finean framework of essence presumably means that one accepts Fine's (1994) famous arguments involving singleton Socrates, i.e., that it is not part of the essence of Socrates that he should belong to his singleton set even though it is metaphysically necessary for him. It is of course on the basis of these arguments that Fine builds the case for the reduction of metaphysical modality to essence: 'far from viewing essence as a special case of metaphysical necessity, we should view metaphysical necessity as a special case of essence' (Fine, 1994: 9). Fine is putting forward a view about the metaphysics of essence and modality, and he is notoriously silent about the epistemology of essence. But if one accepts Fine's logic of essence and understands the implications of the framework, it certainly follows that all essential truths are modal truths. To put it another way: if one accepts the Finean framework, there really is no distinct class of metaphysically necessary truths 'over and above' essential truths. This is just what it means to reduce metaphysical necessity to essence. Now, it's true that this doesn't yet answer the question of how we know (P). But isn't this really just to ask: how do we know that $(\mathrm{P})$ is true? The answer to this question lies in Fine's original arguments: we know (P) because we, or many of us, are convinced by Fine's arguments. The point here is that essence and modality cannot be treated as separate notions at

\footnotetext{
12 Casullo (2020: 603) formulates this principle slightly differently: 'If $p$ is an essential truth then $p$ is a metaphysically necessary truth', but the role of the principle is the same as (P)'s.
} 
all if the Finean framework is accepted. ${ }^{13}$ But here's the source of the confusion: it's important to see that an epistemic subject does not need to know that $(\mathrm{P})$ in order to have knowledge of essence and modality. The point is that any knowledge about essence that a subject may have is knowledge about metaphysical modality by definition. This is the case whether or not the subject knows $(\mathrm{P})$.

To drive the point home, let me very briefly discuss an analogy from philosophy of science that Vaidya and Wallner propose in this connection:

The mere fact that biological facts could be reduced to chemical facts rests on the identification of a bridge principle that can take us from one special science to another special science. The bridge principle would be what justifies one in inferring specific instances of the general reducibility of biological facts to chemical facts. (Vaidya \& Wallner, 2021: 1927.)

It is indeed the case that one would have to know the relevant bridge principle (B-C) that allows reducing biological facts to chemical facts in order to state the reduction from a specific biological fact $b$ to a chemical fact $c$. This is something that we would discuss when we first try to explain $b$ in terms of $c$ - analogously, we need to discuss $(\mathrm{P})$ when we try to construct the overall theory of epistemology of modality on the basis of essence. But if an epistemic subject $S$ knows the chemical fact $c$ and there is indeed 'nothing over and above' $c$ when it comes to biological fact $b$ (as reducibility is often described), then $S$ does not need to know anything about either the general bridge principle between biology and chemistry or its specific instance (B-C) in order to know everything there is to know about $b$. A key difference between this case and the case of modal epistemology is that the reducibility of biology to chemistry is of course highly controversial. So, one might deny that $S$ knows everything there is to know about $b$ just by knowing $c$ because one denies (B-C) and indeed the reducibility of biology to chemistry in general. But in the present context, the Finean framework and hence the truth of the bridge principle $(\mathrm{P})$ is assumed. The upshot is that the role of the bridge principle is not at the level of individual modal epistemology, but rather at the level of our theory of modal epistemology.

Setting aside this confusion, Casullo goes on to raise a more specific problem for Lowe's epistemic reading of possibility precedes actuality, which I should briefly address. Casullo cites a nice passage from Lowe, which I reproduce in part:

[T] he implication of the logical principle [that what is actual is possible] in question is that the possibility of something's being the case is a logically necessary condition - a pre-requisite — of its actually being the case. Hence, empirical evidence can qualify as evidence that something, $p$, is actually the case only on condition that $p$ is at least possibly the case. (Lowe, 2014: 258.)

Lowe concludes in a manner that should now be familiar: knowledge of what is possible precedes and underpins knowledge of what is actual (Lowe, 2014: 259).

\footnotetext{
${ }^{13}$ However, there is an open question about whether this entails an elimination of modality, and Vaidya and Wallner (2021: 1926) argue that it plausible does not. I will leave this issue aside here, as it involves broader questions about the relationship between grounding, reduction, and elimination.
} 
Casullo then reconstructs Lowe's argument based on this and other relevant passages and points out a number of problems with that argument. But rather than try to defend Casullo's reconstructed version of Lowe's argument I think it's more helpful to provide my own reconstruction (which may or may not be faithful to Lowe):

(i) For something to be actual, it must be possible (by logical necessity).

(ii) Therefore, empirical evidence $E$ for the actuality of $p$ qualifies as evidence only if $p$ is possible.

(iii) Therefore, in order to know that something is actually $p$ based on $E$, one must know that $p$ is possible.

It's not difficult to criticise this argument if it is taken out of the broader context of Lowe's modal metaphysics. But as should now be getting clearer, Lowe often seems to have in mind a very specific sense of 'knowing' that $p$ is possible. Specifically, a charitable reading of (iii) suggests something like this: a given body of empirical evidence $E$ can only count in favour of the actuality of $p$ if the essence of $p$ does not preclude its existence. This is a relatively weak claim, but it does rule out some things, e.g., empirical evidence could presumably never count in favour of the actuality of contradictory things. But there are certainly questions that remain. Let me try to make some more progress by bringing in one more critical reply to Lowe.

Independently, Sgaravatti (2016) has picked up on a very closely related issue regarding Lowe's modal epistemology. Sgaravatti outlines what he calls Lowe's Transcendental Argument (TA):

(1) Human beings normally refer in language and thought to individuals and kinds.

(2) One cannot refer in language or thought to something unless one knows what the thing is.

(3) One knows what a thing is just when one knows the essence of that thing.

Therefore,

Human beings normally know the essence of individuals and kinds. (Sgaravatti, 2016: 219.)

Sgaravatti takes issue mainly with premise (3), pointing out that it is incompatible with the most plausible, weak reading of premise (2), whereby it is taken to suggest that whenever one thinks of a given object $o$, one can answer the question 'what is $o$ ?'. Sgaravatti argues that (3) is obviously false, given this reading of (2), because often the answer to 'what is that?' questions has nothing to do with the essence of $o$. I will sidestep some details of Sgaravatti's discussion of (TA) here because Lowe (cf. 2012: 945) is explicitly only committed to a weaker version of the argument, which Sgaravatti labels the Partial Transcendental Argument (PTA). This partial version simply changes premise (3) so that one needs to know a part of the essence. For context, my own understanding of Lowe's view in this regard is that one knows what a thing is just when one knows what kind a thing falls under, i.e., knows the general essence of the thing, so I would also take issue with some of the details of Lowe's framework in this regard. In any case, Sgaravatti challenges this type of view as well, pointing out that even in a Philip K. Dick inspired 
scenario where sophisticated robots look and behave like animals and we wrongly think that a real cat is a robot, it 'seems absurd that one could not think about the cat in that scenario' (Sgaravatti, 2016: 226). But this reaction seems to miss Lowe's sophisticated point, which is roughly that in order to think of something as a cat, i.e., falling under the general kind of living organism, one needs to know (a part of) the general essence of a living organism. So, the upshot is certainly not that one couldn't 'think about the cat' in this scenario, as clearly there could be interaction with this cat. Yet, there is indeed a mistake being made if one does not recognize the cat as a living organism, for a robot cat and a living cat have very different identity and existence conditions.

There is in fact an illustrative discussion of a case like this in Lowe's 2013 book, Forms of Thought, which Sgaravatti, surprisingly, does not cite in his paper. Lowe (2013: 23ff.) discusses the case of Oscar the cat and subject $S$ who does not conceive of Oscar as being a cat. The case that Sgaravatti describes would seem to be precisely like this one, albeit Lowe suggests that we imagine that $S$ conceives of Oscar simply as a hunk of matter (instead of a living organism). He goes on to argue that if this were the case, then $S$ couldn't be in a position to have 'singular thoughts' specifically about Oscar, as opposed to the hunk of matter. The reason for this is precisely because Oscar and the hunk of matter have different identity and existence conditions. The point that Lowe is making is that there must be at least an implicit 'determining factor which makes the thought in question [about Oscar] a thought about the particular, uniquely identifiable object' (Lowe, 2013: 24). Accordingly, the scenario that Sgaravatti describes directly violates this requirement, because the living cat conceived of as a robot cat would mistakenly be associated with a different set of identity and existence conditions.

In summary, Lowe (see 2013: 2) is here defending a view which he labels 'categorialism', according to which a thinker needs to grasp the ontological category of a thing at least implicitly or partially in order to have singular thoughts about the thing as belonging to that category. Importantly, there is in fact no mention of 'knowledge' in this account, so Lowe's considered view does not commit him to anything as strong as Sgaravatti's reconstruction, even in the weakened version that (PTA) suggests.

I conclude this section by acknowledging that despite my attempts to give Lowe's epistemic framework a charitable reading, the critical remarks presented by Horvath, Casullo, Vaidya and Wallner, and Sgaravatti are of course partially justified. Even on a fairly weak reading, the epistemic sense of Lowe's slogans raises some puzzling questions, not all of which Lowe had the time to address. But while I am sympathetic to Lowe's framework and believe that it has much to give, I am not myself fully committed to all aspects of it, especially when it comes to the epistemic reading. So, let me now move on to a case study that develops my own version of the framework, independently of Lowe, and demonstrates how we can put some of these ideas to use. 


\section{The Case of Transuranic Elements}

One of the most puzzling claims of the present framework is that we can at least sometimes come to know the essences of non-existing entities. Let me consider one example of such a case in more detail. The example I have in mind concerns transuranic elements - elements with an atomic number greater than 92, i.e., that of uranium. The point could be made even more strikingly for superheavy elements, which have an atomic number greater than 103. Transuranic elements are generally short-lived (and radioactive). What is important is that many of the transuranic elements were only synthesised after their existence was predicted. With the help of the principles underlying the periodic table of elements, scientists have been able to predict the existence of a number of yet to be discovered elements and to give highly accurate estimates of their chemical properties. Some of these elements may be naturally occurring, but some of them may have come into existence for the first time when we synthesised them.

The main lesson of this example is that if we did not have some prior understanding of the (partial) essence of entities such as transuranic elements, then we would not be in a position to establish their existence when we do in fact encounter them. I propose that this lesson generalises to other cases as well, even though it is important to remember that we do not need to commit to the necessity of this epistemic priority. Indeed, some of the evidence to be discussed fits just as well with the thesis (E-EN) outlined in the introduction: knowledge of $x$ 's existence is entangled with knowledge of $x$ 's essence. However, the most illuminating cases concern scientific predictions, e.g., cases where the chemical properties of yet to be discovered elements can be predicted with high accuracy. I suggest that this is a clear case of a partial grasp of an entity's essence prior to its existence, and delivers an interesting connection between the present framework and scientific inquiry.

Lowe himself sometimes used the example of transuranic elements, so let me cite his own words:

Prior to the actual synthesis of various transuranic elements-prior, indeed, to the actual existence, anywhere in the universe, of certain of these elementschemists knew what they would be. That is to say, they grasped the real definitions of certain as yet non-existent transuranic elements. (Lowe, 2014: 267.)

Lowe didn't develop this example any further, but the basic idea fits my version of the framework as well. There is a slight complication here relating to one's preferred ontology of natural kinds. If we regard natural kinds such as transuranic elements to be substantial universals, like both Lowe and I do, then on a typical Aristotelian line, these kinds do not exist unless they have instances. ${ }^{14}$ However, a plausible view to take here is that such universals themselves do not exist 'in' time, even though their instances do. So, as long as a kind will have instances at some point in the past

\footnotetext{
14 Substantial kind universals are a sui generis category of universal, distinct from property universals. Regarding Lowe's views on kind universals and their instantiation, see also Keinänen and Hakkarainen 2017, and Keinänen and Tahko 2019.
} 
or in the future, it may be regarded to exist. ${ }^{15}$ In this case, such kinds would not strictly speaking be non-existent. This of course suggests a type of four-dimensional, eternalist picture, whereby existence at any given instance of time can be taken as equally real. ${ }^{16}$ Still, there may be transuranic elements that will never have instances - perhaps they are too unstable to be synthesised or we just never get around to synthesising them. So, we still need to be able to consider the truly non-existent cases as well. ${ }^{17}$

What makes the present framework so versatile is precisely the fact that we can consider the essences of non-existent entities as well, and indeed we can do so without making any Meinongian commitments or resorting to any mysterious tools. In fact, the process is exactly the same as it is in the case of existing entities, except for the difference that we cannot directly study these entities by empirical means. What we can do is consider what it would take for some entity to exist. The caveat is that it may be very difficult to determine this.

Let me finally describe an actual example concerning transuranic elements. As early as 1922, Niels Bohr described the possibility of transuranic elements and predicted the configuration of the hypothetical element $\mathrm{Z}=118$, ununoctium (see Kragh, 2013). He went further and suggested that this element would be a noble gas with chemical properties similar to radon. This superheavy element, now called oganesson, is the heaviest that has been synthesised. We do not yet know whether Bohr's predictions regarding the chemical properties of oganesson are fully correct, but he was right about its electron structure, and it is classified as a noble gas.

A particularly striking aspect concerning the example of superheavy elements is just how difficult it is to confirm their existence. Kragh (2017) describes the troubled history of $\mathrm{Z}=118$ as follows:

In the summer of 1999 a group of 15 researchers at Lawrence Berkeley National Laboratory (LBNL), including the SHE veteran Albert Ghiorso, announced that it had detected two new elements, one with $\mathrm{Z}=118$ and the other its decay product with $Z=116$. [...] However, what a[t] first appeared to be a great success soon turned into something like a nightmare. Neither the Darmstadt group nor other European laboratories were able to confirm the data on the reported synthesis of the nuclide of mass number 293. And when the Berkeley scientists tried to repeat and improve the experiments no sign of element 118 turned up. Eventually it dawned upon them that something was wrong. After several committees had examined the matter it was concluded

\footnotetext{
15 There is a helpful exchange on this topic between Kistler (2004) and Lowe (2004).

16 I should note though that Lowe (e.g., 2006b) has defended a view about time that comes close to presentism instead, and this view is arguably compatible with the thought at hand as well, but I will not enter into the details of this. As is usual with Lowe, his precise view typically cannot be pinned down with a simple label like 'presentism'!.

17 There is of course another line that one could take here, namely the Platonic one, whereby universals exist in a Platonic realm. In that case, one might think that all possible natural kinds have a corresponding Platonic universal that does exist, if only in the Platonic heaven. But since I am not at all sympathetic to this line of thought myself - and nor is Lowe - I will here set aside the Platonic solution.
} 
that the records of 1999 were unreliable. Worse, some of the reported data were not real but had been fabricated [...]. (Kragh, 2017: 17.)

The scientist responsible for the fabricated data was fired and in 2002 the claim of synthesising element 118 was redacted by the remaining 14 researchers. After the scandal, it took until 2016 before the discovery of the element was finally approved after further experiments.

The reason why I have described this case in such detail is that it perfectly illustrates how 'possibility precedes actuality' as I understand this slogan in my version of the framework at hand. We had a (correct) prediction of the structure of oganesson almost 100 years ago from Bohr, firmly establishing the possibility of such an element, but it took several attempts to bring that structure into existence, and even when we did, that existence was rather fleeting and uncertain (the element has a half-life in the range of $0.89 \mathrm{~ms}$ ) - it could easily have been the case that we never managed to synthesise this element. The uncertainty regarding the existence of superheavy elements with such short half-lives may seem like an extreme case, but the point that I wish to highlight is that this is no special case: as successful as our scientific efforts are, there is great uncertainty about the existence of many things postulated in scientific theories. Consider dark matter, strings, electron substructure, the nature of the wavefunction, the size of the universe... One might insist that these are just more extreme and speculative cases from physics. But we could just as well consider the existence of things like biological species, social groups, and consciousness. Insofar as we do not agree about the identity and existence conditions of these things, we are not in a position to agree about their existence: if we are not in agreement about what something is, then how can we establish that it exists? We may agree that something exists, say, something like dark matter is required to explain why the expansion of the universe has not been slowing due to gravity, but has been accelerating instead. But we need to know more than this before we can confidently say that dark matter exists. In particular, to establish the existence of some thing of a specific kind, we need to specify its identity and existence conditions - its essence - otherwise, we might very well be looking at it without recognising it as the kind of thing it is. ${ }^{18}$

\footnotetext{
18 There is much more to be said of course. For instance, what is a 'thing' of any category? This is a related question explored in Fiocco 2019, but which I must leave aside. The general points here are roughly in line with the views that Lowe presents in his 2013 book Forms of Thought, but I don't expect that Lowe would have accepted the version of the framework that I am putting forward here. There are of course further controversial matters that arise from this, especially regarding reference. I do not have the space to discuss all these issues here, nor do I wish to fully commit to Lowe's views in this regard. For instance, do we need to grasp the complete essence of something before we can refer to it in thought? As discussed in Sect. 3, the plausible answer is 'no' - a partial grasp may be sufficient. Another tricky issue concerns the question of (prelinguistic) infants, who may not comprehend the relevant criteria of identity. Lowe (2013: 22ff.) explains his position by considering the case of a cat being observed by an infant. What does it take to have singular thoughts about a cat rather than a hunk of matter? Lowe insists that even though an infant hasn't fully grasped the adult concept of an animal and its associated criterion of identity, they would still need to have an implicit grasp of some categorial concept with an associated criterion of identity - a concept which we might describe as being an infantile precursor to the fully fledged adult concept of an animal' (Lowe 2013: 26).
} 
What I hope to have made clear by now is that we do need a framework for understanding how we can consider the essences of non-existent entities - the reason is simply that we are probably doing so all the time in scientific contexts, whether we like it or not. But one might still worry that in order for our talk about non-existent entities to be meaningful, there must be something that makes that talk true. What are the truthmakers for our statements about the essences of non-existent entities, such as yet to be synthesised transuranic elements? On the view about essence that I am advocating, whereby essences are not entities and hence no further addition to being, the truthmakers can't be the essences of those non-existent entities - only entities can act as truthmakers. ${ }^{19}$ So, the truthmakers must be drawn from the things that actually do exist. Here as well we can use the history of the search for superheavy elements as our guide. Actually, we could go further into the past and consider Mendeleev's work, who made several predictions based on his periodic table of elements. For instance, Mendeleev predicted the existence of gallium (Ga), scandium $(\mathrm{Sc})$, and germanium $(\mathrm{Ge})$ as well as many of their chemical properties. These were soon discovered and found to closely match his predictions. Recall that these 'predictions' may be regarded as an example of what Lowe might call 'grasping' an entity's essence. So, what were Mendeleev's predictions based on? Well, Mendeleev himself had very high standards of what counts as a successful prediction - and not all of his suggestions were accurate to this level:

By 'prediction', Mendeleev meant not only that an element of the right atomic weight would be found but also that it would have properties, such as highest oxidation state, oxyacid formation, atomic volume, metallic character and so on, corresponding to those of lighter analogues in the same group. In this sense he made only three complete predictions. His method, illustrated in detail only for these three, was to interpolate from lower analogues - and higher ones if available — and from neighbouring elements. (Stewart, 2017: 4.)

The method seems pretty clear: interpolate from the closest analogues, based on the structure and properties of elements already known to us. I should highlight, again, that this looks to be very much in line with the idea that our knowledge of essence is in some important respects entangled with our knowledge of existence. Now, the predictions that Mendeleev made about undiscovered elements did not concern nonnaturally occurring superheavy elements, so we can say that Mendeleev's statements concerning yet to be discovered elements were made true by the actually existing samples of the predicted elements instead. But what is important here is the method: once we have observed that there is a pattern that enables us to predict the existence and properties of hitherto undiscovered elements, we can put forward counterfactuals that are true (if they are true) in virtue of the structural properties we are already

\footnotetext{
19 I am again deviating from Lowe's views, but it is helpful to compare my view to his. On Lowe's (2006a: Ch. 11) view, only facts can act as truthmakers. But Lowe understand facts as complex 'worldly' entities (2006a: 183), individuated and 'constituted' by their worldly constituents, such as objects, properties, and relations (see also Audi 2012: 686). So, to bring the present approach in line with Lowe's understanding of truthmaking, we might say that only entities can act as constituents of facts, i.e., truthmakers.
} 
aware of. For instance, we can make a number of predictions about $\mathrm{Z}=119$, ununennium, which is predicted to be an alkali metal. But since the element has not yet been synthesised, the counterfactual 'If element 119 existed, it would be an alkali metal' cannot be made true by the entity itself. Rather, assuming that the counterfactual is true, it is made true by properties that may be associated with the already existing alkali metals, such as the property of having one valence electron in the outermost s-orbital. This property, incidentally, is also responsible for the high reactivity of alkali metals. So, if element 119 would share at least this property with the existing alkali metals, then at least some of the counterfactuals concerning it are made true by already existing properties. It is precisely this type of complex entanglement of our knowledge of existence and knowledge of essence that makes it difficult to put forward any absolute sense of the slogan 'essence precedes existence' or its converse. We could discuss many more examples like this from the history of science and also from cases outside physics and chemistry, but I believe that we now have enough material to move on.

\section{Whither Actuality?}

Ultimately, we want to know what is actual. This is what both philosophy and science aim to do. But our tools to determine what is actual are limited and we can make mistakes. This is why I have taken my time above to describe why much of our efforts should be focused on how we can know what is possible, and this, to me, is the core of Lowe's idea that possibility precedes actuality, as I understand and develop on it. But more should be said about the relationship of the possible and the actual in the framework I am proposing. Here, I'd like to focus on three things:

(i) Actuality must consist of entities that could exist.

(ii) There are many entities whose essences do not preclude them from existing.

(iii) Only those entities that could exist together can inhabit actuality.

The first point (i) may seem trivial, but it re-iterates an important issue. Given that some entities could not exist, i.e., they are impossible, they cannot be actual. The problem is, to be able to determine what could exist, we should already have some idea about the fundamental structure of reality. I previously mentioned entities that possess contradictory properties as one example, but I admit that even this may be controversial, since it assumes that something like the law of non-contradiction governs reality. I do believe that the law of non-contradiction does indeed have this important role (following Tahko, 2009), but after that, things soon get more controversial. As I noted early on, one thing that plausibly determines the identity and existence conditions of entities is the categorial structure of reality, which delimits what is possible. But the nature of that structure is obviously subject to debate. Another plausible delimiting factor are laws of nature, but whether one considers these laws to be metaphysically necessary or merely physically necessary is also debatable. If violations of the actual laws of nature are metaphysically possible, then we cannot rule out entities violating them as metaphysically impossible. To take a 
simplified example, consider tachyons, the hypothetical particles capable of superluminal travel. If it is a law of nature that faster than light travel is not possible, and if that law is metaphysically necessary, then tachyons are metaphysically impossible. But simply the fact that such entities and their respective identity and existence conditions have been considered (and not just in Star Trek) shows us that there is uncertainty here. It seems likely that, perhaps unwittingly, we sometimes do consider the essences of entities that are in fact metaphysically impossible. I will not enter into the debate regarding the modal status of laws here (but see Tahko, 2015). Rather, I just wish to make the simple point that the initial delimitation of what is possible varies radically depending on one's views about these other matters.

The second point (ii) highlights the fact that even if we do have some basic principles in place to delimit the space of metaphysical possibility, there is still going to be a vast number of possible entities, all of them candidates for actually existing entities. But this point can really only be appreciated in connection to the third point (iii), which concerns the restrictions regarding the combinations of possible entities. It is this third point which finally gives us a little bit more to work with, as we need to appreciate the fact that essences should not be considered in isolation. What this means in practice is that when we consider the identity and existence conditions of some possible entity, these conditions may refer to other entities, either precluding the existence of these entities at the same time or requiring it. ${ }^{20}$ An example may help: if we assume that the usual (overly simplified) story about the microstructural essence of water is correct, then the essence of water refers to the essences of hydrogen and oxygen. Accordingly, water's essence cannot be fully stated without stating something about the essences of hydrogen and oxygen as well. As I've already suggested, these dependencies among the essences of various entities may be described in terms of various forms of ontological dependence. Once all these conditions are in place and all the dependencies among the possible entities are included, a properly delimited space of metaphysical possibility emerges. Each viable combination of these conditions is a 'possible world' - if one wishes to resort to that terminology.

Notice that I have not used the possible worlds terminology at all since I do not regard the various possible combinations of compatible essences to be 'worlds' in any relevant sense. Rather, each of these combinations is a candidate for what is actual. Because is it so difficult to trace all the dependencies and indeed to even come to an agreement about what is metaphysically possible in the first place, it is not so easy to come up with these (complete) candidates for actuality. This is what I regard to be a core idea behind the slogan 'possibility precedes actuality': we are forced to operate in the realm of possibility when trying to determine the combinations of essences that could 'belong' to actually existing entities. I must stress that this is not just a philosophical point, as all our scientific endeavours are in the same boat. This was demonstrated by the case study regarding transuranic elements. So, the result should not be considered negative or pessimistic; I would insist that this is in fact a key part of the scientific method as well.

\footnotetext{
${ }^{20}$ Note that this is distinct (although not entirely unrelated) from so called 'collective essence', the idea that some truths are essential to many entities taken together. See Zylstra 2019 for discussion.
} 
Questions about the resulting ontological picture will remain. ${ }^{21}$ One may ask: does at least something need to exist for there to be any essences in the first place? In other words, would there be any essences if nothing existed? In theory, I think that the account presented (and indeed also Lowe's version of it) could be made compatible with the idea that even if nothing existed, there would be essences. Given the notion of essence that I favour, all it takes for there to 'be' essences is that there are conditions for the identity and existence of entities. So, even if nothing actually existed, we could presumably still have such conditions in place. Recall that the identity and existence conditions are ultimately derived from the fundamental categorial structure of reality. That structure could in principle be in place even if nothing existed. However, this may go against the Aristotelian spirit in which I have presented the account at hand, since on this view there must be some instances of a category for that category to exist. In any case, the question is somewhat theoretical since it seems clear that something does exist, at least if we rule out the most extreme forms of scepticism. Now, if we reformulate the thought and ask which came first, essence or existence, then I think that on the line I am taking this does not really matter, because as previously noted, I am explicitly working in a fourdimensional, eternalist framework.

Notice, finally, that nothing I've said contradicts the well-known principle that actuality entails possibility. Of course it does: actuality is just one of the many possible combinations of essences. But this is a point at the level of the metaphysics of modality rather than modal epistemology. If we do not know what is actual, then we can do very little with the fact that actuality entails possibility. Almost no one questions the inference from actuality to possibility, but I would like to note one important contribution regarding this issue. ${ }^{22}$ Hanrahan (2017) has argued that the inference from the actual to the possible is merely explicative, but in modal epistemology it is sometimes used in an ampliative fashion. Hanrahan is explicitly operating in the context of modal epistemology and the question of whether we are justified in formulating beliefs about, say, future or past occurrences of everyday phenomena based on veridical perception. I have of course been operating in a somewhat different context, focusing on scientific inferences, but the basic point holds, and I believe that my analysis bolsters Hanrahan's view regarding it: the explicative inference from actuality to possibility alone is not going to help us much in modal epistemology. If we wish to use it in an ampliative manner, a further story of why it can be reliably used is required. The positive story that Hanrahan presents to salvage the ampliative use of the principle in justifying our everyday or ordinary modal claims is based on assumptions about the uniformity of nature (mainly, laws of nature). I will not discuss the details of her proposal here as my focus is of course more on the scientific context, which requires, as I have demonstrated, sometimes considering violations of laws (or alternative laws) as well.

Even if I have managed to convince the reader that the resulting framework is worth considering, there is another important task that remains, namely, to

\footnotetext{
21 Thanks to an anonymous reviewer for drawing my attention to the one that follows.

22 Thanks to an anonymous reviewer for bringing my attention to this contribution.
} 
determine our confidence regarding the actuality of the various possible entities whose essences we may grasp. In many cases, we can fortunately say that this confidence is very high. I would be very surprised if we turned out to be incorrect about the existence of something very much like the elements described in the periodic table. It is of course still entirely possible that our knowledge of these elements will be refined in various ways. However, these mostly epistemic issues go somewhat outside the scope of this paper, and, in any case, there are other well-rehearsed discussions about how best to understand the practice of revising our beliefs about actuality (consider, e.g., the web of belief, real patterns, belief revision theory, and robustness analysis). I hope to return to this topic elsewhere.

Acknowledgements I would like to thank the MetaScience team (Francesca Bellazzi, Toby Friend, Samuel Kimpton-Nye, and Vanessa Seifert), Ken Aizawa, Stuart Glennan, Michael Lacey, and Sanna Mattila, as well as two anonymous reviewers for Erkenntnis, and audiences at the 9th WFAP 2020 Graduate Conference on Problems Facing Modality in Vienna and the Neo-Aristotelian Perspectives on Persistence and Modality conference in Mainz for many helpful discussions and comments on earlier versions of this paper. The research for this paper has received funding from the European Research Council under the European Union's Horizon 2020 research and innovation programme, grant agreement no 771509, The Metaphysical Unity of Science ('MetaScience') Consolidator grant.

Open Access This article is licensed under a Creative Commons Attribution 4.0 International License, which permits use, sharing, adaptation, distribution and reproduction in any medium or format, as long as you give appropriate credit to the original author(s) and the source, provide a link to the Creative Commons licence, and indicate if changes were made. The images or other third party material in this article are included in the article's Creative Commons licence, unless indicated otherwise in a credit line to the material. If material is not included in the article's Creative Commons licence and your intended use is not permitted by statutory regulation or exceeds the permitted use, you will need to obtain permission directly from the copyright holder. To view a copy of this licence, visit http://creativecommons.org/licen ses/by/4.0/.

\section{References}

Audi, P. (2012). Grounding: Toward a theory of the in-virtue-of relation. Journal of Philosophy, 109(12), 685-711.

Brody, B. A. (1973). Why settle for anything less than good old-fashioned aristotelian essentialism. Noûs, 7(4), 351-365.

Casullo, A. (2015). Four challenges to the a priori-a posteriori distinction. Synthese, 192, 2701-2724.

Casullo, A. (2020). Is knowledge of essence the basis of modal knowledge? Res Philosophica, 97(4), 593-609.

Correia, F. (2006). Generic essence, objectual essence, and modality. Nô̂s, 40(4), 753-767.

Correia, F. (2008). Ontological dependence. Philosophy Compass, 3(5), 1013-1032.

Correia, F. (2012). On the reduction of necessity to essence. Philosophy and Phenomenological Research, 84(3), 639-653.

Fine, K. (1994). Essence and modality. Philosophical Perspectives, 8, 1-16.

Fine, K. (1995). Ontological dependence. Proceedings of the Aristotelian Society, 95, 269-290.

Fine, K. (2005). Modality and tense. Clarendon Press.

Fiocco, M. O. (2019). What Is a thing? Metaphilosophy, 50(5), 649-669.

Hanrahan, R. (2017). The actual and the possible. Journal of Philosophical Research, 42, 223-242.

Horvath, J. (2014). Lowe on modal knowledge. Thought, 3, 208-217.

Keinänen, M., \& Hakkarainen, J. (2017). Kind instantiation and kind change - a problem for four-category ontology. Studia Neoaristotelica, 14(2), 139-165.

Keinänen, M., \& Tahko, T. E. (2019). Bundle theory with kinds. The Philosophical Quarterly, 69(277), $838-857$. 
Kimpton-Nye, S. (2021). Can hardcore actualism validate S5? Philosophy and Phenomenological Research, 102(2), 342-358.

Kistler, M. (2004). Some problems for lowe's four-category ontology. Analysis, 64(2), 146-151.

Koslicki, K. (2012). Varieties of ontological dependence. In F. Correia \& B. Schnieder (Eds.), Metaphysical grounding: Understanding the structure of reality (pp. 186-213). Cambridge University Press.

Koslicki, K. (2018). Form, matter, substance. Oxford University Press.

Kragh, H. (2017). The search for superheavy elements: historical and philosophical perspectives. arXiv: 1708.04064v1 [physics.hist-ph]

Kragh, H. (2013). Superheavy elements and the upper limit of the periodic table: Early speculations. The European Physical Journal H, 38, 411-431.

Lowe, E. J. (1998). The possibility of metaphysics. Oxford University Press.

Lowe, E. J. (2004). The four-category ontology: Reply to Kistler. Analysis, 64(2), 152-157.

Lowe, E. J. (2006a). The four-category ontology: A metaphysical foundation for natural science. Oxford University Press.

Lowe, E. J. (2006b). How real is substantial change? The Monist, 89(3), 275-293.

Lowe, E. J. (2008). Two notions of being: Entity and essence. Royal Institute of Philosophy Supplements, $83(62), 23-48$.

Lowe, E. J. (2012). What is the source of our knowledge of modal truths? Mind, 121, 919-950.

Lowe, E. J. (2013). Forms of thought. Cambridge University Press.

Lowe, E. J. (2014). Essence vs. intuition: An unequal contest. In A. R. Booth \& D. P. Rowbottom (Eds.), Intuitions (pp. 256-268). Oxford University Press.

Mallozzi, A. (2021). Superexplanations for counterfactual knowledge. Philosophical Studies, 178, 1315-1337.

Oderberg, D. (2011). Essence and properties. Erkenntnis, 75, 85-111.

Roca-Royes, S. (2010). Modal epistemology, modal concepts and the integration challenge. Dialectica, 64(3), 335-361.

Rosen, G. (2015). Real definition. Analytic Philosophy, 56, 189-209.

Sgaravatti, D. (2016). Is knowledge of essence required for thinking about something? Dialectica, 70(2), 217-228.

Smith, B., \& Mulligan, K. (1983). Framework for formal ontology. Topoi, 1, 73-85.

Spinelli, N. (2018). Essence and Lowe's regress. Organon F, 25(3), 410-428.

Stewart, P. J. (2017). Mendeleev's predictions: Success and failure. Foundations of Chemistry, 21, 3-9.

Tahko, T. E., \& Lowe, E. J. (2020). Ontological dependence. In E. N. Zalta (Ed.), The Stanford encyclopedia of philosophy Fall 2020 Edition. http://plato.stanford.edu/archives/fall2020/entries/depen dence-ontological/.

Tahko, T. E. (2009). The law of non-contradiction as a metaphysical principle. Australasian Journal of Logic, 7, 32-47.

Tahko, T. E. (2015). The modal status of laws: In defence of a hybrid view. The Philosophical Quarterly, 65(260), 509-528.

Tahko, T. E. (2017). Empirically-informed modal rationalism. In R. W. Fischer \& F. Leon (Eds.), Modal epistemology after rationalism (pp. 29-45). Springer.

Tahko, T. E. (2018). The epistemology of essence. In A. Carruth, S. C. Gibb, \& J. Heil (Eds.), Ontology, modality, mind: Themes from the metaphysics of E. J. Lowe (pp. 93-110). Oxford University Press.

Vaidya, A. (2010). Understanding and essence. Philosophia, 38, 811-833.

Vaidya, A. (2017). Modal knowledge: Beyond rationalism and empiricism. In R. W. Fischer \& F. Leon (Eds.), Modal epistemology after rationalism (pp. 85-114). Springer.

Vaidya, A., \& Wallner, M. (2021). The Epistemology of modality and the problem of modal epistemic friction. Synthese, 198, 1909-1935.

Wallner, M. (2020). The structure of essentialist explanations of necessity. Thought: A Journal of Philosophy, 9(1), 4-13.

Williamson, T. (2013). How deep is the distinction between a priori and a posteriori knowledge? In A. Casullo \& J. C. Thurow (Eds.), The A Priori in Philosophy (pp. 291-312). Oxford University Press.

Zylstra, J. (2019). Collective essence and monotonicity. Erkenntnis, 84, 1087-1101.

Publisher's Note Springer Nature remains neutral with regard to jurisdictional claims in published maps and institutional affiliations. 